\title{
Comparison of two automatic methods for measuring grazing behaviour
}

\author{
F Blanc ${ }^{1}$, A Berger 2 \\ IINRA, LAHM, Theix, 63122 St-Genès-Champanelle, France ; Institute for Zoo Biology \\ and Wildife Research, Alfred-Kowalke Str 17, 10315 Berlin, Germany
}

Visual observation of grazing behaviour is time consuming and not easy during night. So, automatic recording systems of grazing activities are interesting insofar as they allow to collect information during long periods and night.

We compared two of these systems. The first one, APEC, was developed by the INRA station, Theix. It measures, with a good reliability, eating and rumination by recording jaw movements (Brouillette et al, 1993, JDS, 76 , suppl.1, 405). APEC includes a pneumatic transducer, fixed under the jaw, and a data logger. All jaw movements create pressure variations which are detected every 2.5 seconds by an electronic transducer which converts pneumatic impulses to binary notation. Data stored are collected after handling the animal and connecting the APEC with a computer. Then, values are categorised into eating, ruminating and resting by an interpretative software program. The second system, ETHOSYS, was developed by the Institute of Zoo- and Wildlife Research, Berlin. A collar realises an indirect measurement of the activities through two sensors. One measures acceleration, the second the head position. Thus, activities are identified on the basis of animal movements, head position and rhythms of neck movements. Logic functions, included into the collar, interpret the signal patterns and categorise them into eating, ruminating, activity with head down and total activity. Interpretations are registered each second by a microcontroller which summarises the results in programmed intervals from 1 to 60 minutes and stores them in a memory. Data collection is automatic as data files can be sent to a receiving station by radio telemetry.
To compare these two systems we equipped 3 grazing ewes with the same combination of one APEC and one ETHOSYS collar, whose sampling interval was 5 minutes. Data were collected for total periods going from $90 \mathrm{~h}$ to $116 \mathrm{~h}$. For each of these 3 recording periods, we compared the average per hour of time spent in one activity and we calculated from these averages the correlation coefficients between : (1) Eating measured by APEC and by ETHOSYS, (2) Eating measured by APEC and activity head down measured by ETHOSYS, (3) Ruminating measured by APEC and ETHOSYS.

The measurements of grazing activities obtained from the two methods are highly correlated, particularly conceining eating (table). Correlations for rumination differ between the recording periods but are higher than 0.5 .

Considering APEC as the reference we observe that the activity called "head down" by ETHOSYS gives a better estimation of eating than the activity called "eating", which certainly concerns only biting.

In conclusion, ETHOSYS gives a good estimation of eating through the "activity head down". As for rumination, APEC is more precise as it realises direct records of jaw movements. The disadvantages of APEC are that it is time consuming in application and its storage capacity is limited to 6 days. Although it realises an indirect measurement of behaviour ETHOSYS is interesting specially for the study of free ranging herbivores thanks to its simple application, the automatic data transfer and its capacity to work independently for a year.

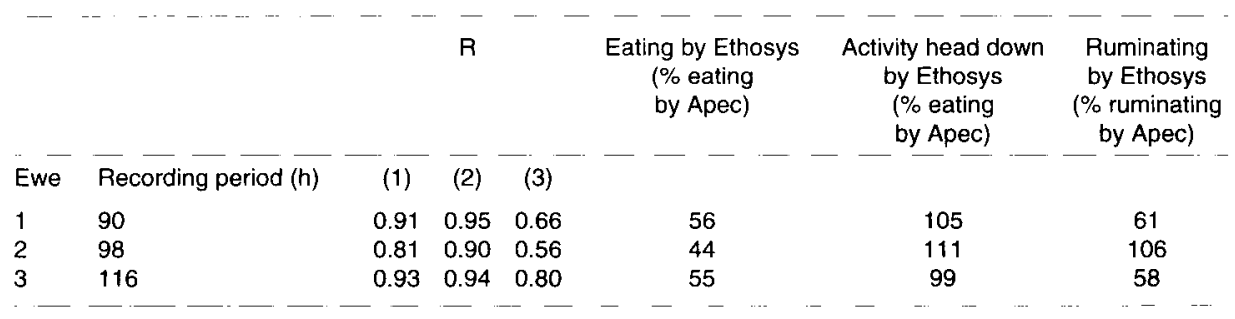

